\title{
RELATOS DE PESQUISAS
ANÁLISE DA PRODUÇÃO CIENTÍFICA BRASILEIRA E
PORTUGUESA SOBRE O TEMA REPOSITÓRIO:
UM ESTUDO A PARTIR DO RCAAP
}

\author{
Ana Paula Matos Bazilio \\ Doutoranda em Ciência, Tecnologia e Sociedade pela Universidade Federal \\ de São Carlos, Brasil. Bibliotecária da Universidade Federal Fluminense, \\ Brasil. \\ E-mail: anapaulambazilio@gmail.com \\ Luciana de Souza Gracioso \\ Doutora em Ciência da Informação pela Universidade Federal Fluminense, \\ Brasil. Professora da Universidade Federal de São Carlos, Brasil. \\ E-mail: lugracioso@yahoo.com.br
}

\begin{abstract}
Resumo
Iniciativas de gestão do conhecimento contribuem para o aperfeiçoamento e a potencialização do conhecimento científico, de forma a suscitar a geração de novos conhecimentos, a otimização de recursos, o crescimento institucional e o progresso da ciência. Neste cenário, os repositórios se configuram como ferramentas que contribuem para esses processos, tanto de comunicação científica quanto para o de gestão de conhecimento. Neste contexto foi identificada a necessidade de investigar, em uma perspectiva exploratória e descritiva, como tem se configurado a produção científica, relacionada ao Repositório, nas pesquisas em Ciência da Informação brasileira e portuguesa, a fim de analisar, de modo mais pontual, como os repositórios têm sido conceituados e caracterizados nestas pesquisas de língua portuguesa. Para tanto, foram selecionadas teses e dissertações junto ao Portal Repositório Científico de Acesso Aberto de Portugal (RCAAP), que posteriormente foram analisadas seguindo categorias definidas a partir dos objetivos da pesquisa. Como resultado geral constatou-se que o repositório digital é o primeiro repositório a surgir, sendo um conceito mais amplo, logo após surgem os conceitos de repositórios institucionais de Crow (2002) e Lynch (2003) e a confirmação que em geral os repositórios são conceituados conforme o tipo de material depositado, área de pesquisa ou alguma finalidade específica.
\end{abstract}

Palavras-chave: Comunicação científica. Repositórios. Repositório Científico de Acesso Aberto de Portugal - RCAAP. Acesso aberto.

\section{ANALYSIS OF BRAZILIAN AND PORTUGUESE SCIENTIFIC PRODUCTION ON THE REPOSITORY THEME: A STUDY FROM RCAAP}

\begin{abstract}
Knowledge management initiatives contribute to the improvement and enhancement of scientific knowledge, in order to encourage the generation of new knowledge, the optimization of resources, institutional growth and the progress of science. In this scenario, the repositories are configured as tools that contribute to these processes, both for scientific communication and for knowledge management. In this context, the need to investigate, in an exploratory and descriptive perspective, how the scientific production related to the Repository has been configured in Brazilian and Portuguese Information Science research, in order to analyze, in a more punctual way, how repositories have been conceptualized and characterized in these Portuguese-language research. For that, theses and dissertations were selected from the Scientific Open Access Scientific Repository Portal of Portugal (RCAAP), which were subsequently analyzed following categories defined based on the research objectives. As a general result, it was found that the digital repository is the first repository to emerge,
\end{abstract}

Perspectivas em Gestão \& Conhecimento, João Pessoa, v. 10, n. 3, p. 246-261, set./dez. 2020. DOI: https://dx.doi.org/10.22478/ufpb.2236-417X.2020v10n3.55902

http://periodicos.ufpb.br/ojs2/index.php/pgc. ISSN: 2236-417X. Publicação sob Licença (cc) EY-NC-ND 
being a broader concept, shortly after the concepts of institutional repositories by Crow (2002) and Lynch (2003) and the confirmation that in general the repositories are conceptualized according to the type of material deposited, research area or some specific purpose.

Keywords: Scientific communication. Repositories. Scientific Open Access Scientific Repository Portal of Portugal - RCAAP. Open access.

\section{INTRODUÇÃO}

A relevância desta pesquisa centra-se no papel que os repositórios podem exercer nos novos rumos da comunicação científica. Nas últimas duas décadas - mais especificamente, desde 2002 -, com a instauração do acesso aberto, cientistas e pesquisadores reconhecem a importância de comunicar, divulgar e socializar o conhecimento científico para os seus pares e para toda a sociedade em geral. O ponto de partida da presente pesquisa parte do entendimento e da defesa de que os avanços promovidos pela consolidação e uso de repositórios, vem redefinindo os fluxos da comunicação científica e nesta perspectiva a pesquisa encontra consonância com as afirmações de Weitzel (2006, 2019); Santos Júnior (2010); Costa e Leite (2017); Carvalho e Gouveia (2017); Gama e Carvalho (2017); e Gomes (2017).

Os repositórios, sejam eles institucionais, digitais, acadêmicos, ou ainda, de dados e $e$ prints, confirmam-se cada vez mais, como um dos mais potentes recursos de gestão e promoção do acesso aberto as produções científicas, em uma perspectiva global. Alguns países têm se destacado na proposição de produtos que otimizem e aprimorem os sistemas de gestão dos mais variados materiais que compõe acervos e coleções nestes repositórios. Neste sentido, se reconhece notadamente a relevante contribuição de Portugal, nessa mesma perspectiva, e de modo mais explícito, a partir dos esforços de consolidação deste país no desenvolvimento do Projeto Repositórios Científicos de Acesso Aberto de Portugal, sendo o Repositório Científico de Acesso Aberto de Portugal (RCAAP) um de seus componentes. Este repositório contempla os trabalhos brasileiros indexados no Portal brasileiro de publicações científicas em acesso aberto (oasisbr) que por sua vez também indexa os materiais do RCAAP.

Neste contexto, foi identificada a necessidade de investigar, em uma perspectiva exploratória e descritiva, como tem se configurado a produção científica, relacionada ao Repositórios, no referido portal português, almejando analisar, via este portal, a totalidade das pesquisas desenvolvidas sobre o tema, permitindo, em uma segunda fase de análise, averiguar pontos de convergência e divergência nestas produções em relação as conceituações e definições que estão sendo produzidas cientificamente, nestes países, sobre os repositórios, e especial, no âmbito da Ciência da Informação. Diante do exposto acima, o objetivo do presente estudo foi o de discorrer sobre as conceituações e definições que estão sendo produzidas cientificamente, relacionadas aos Repositórios, no contexto da Ciência da Informação, tanto na produção brasileira quanto portuguesa.

Para o alcance dos objetivos propostos, foi realizada inicialmente uma pesquisa no Repositório Científico de Dados Abertos de Portugal (RCAAP), com os termos "repositório digital", "repositório institucional" e "repositório científico", em idioma português considerando a abrangência temporal total da base, isto é: 1806 até 2020. Os tipos de materiais pesquisados foram dissertações de mestrado e teses, a coleta de dados foi em julho de 2020. Optou-se pelo RCAAP por ser um diretório que agrega informações de importantes repositórios portugueses e brasileiros, como, a exemplo, o portal brasileiro de publicações científicas em acesso aberto do Instituto de Ciência e Tecnologia - IBICT (OASISBR), que tem parceria com a Biblioteca Digital de Teses e Dissertações Brasileiras (BDTD). O RCAAP reúne

Perspectivas em Gestão \& Conhecimento, João Pessoa, v. 10, n. 3, p. 246-261, set./dez. 2020. 
documentos de caráter científico e acadêmicos - como artigos científicos, teses e dissertações, comunicação e conferência - distribuídos por repositórios e diretórios, além de renomadas revistas científicas brasileiras, portuguesas e de outros países.

Este estudo justifica-se pelo papel que os repositórios exercem no processo de comunicação científica, proporcionando, assim, mais agilidade e maior visibilidade nesse processo, e tornando necessário que os cientistas e pesquisadores conscientizem sobre a importância destes para a propagação dos resultados de suas pesquisas de forma ampla, veloz e sem barreiras de custos ou de acesso. Conforme os resultados quantitativos e qualitativos desta pesquisa sobre a temática, vimos que as universidades e instituições de pesquisa carecem de mais estudos sobre o tema repositórios e uma melhor sistematização dos conceitos dos diferentes tipos de repositórios na literatura da Ciência da Informação. Este trabalho também se fundamenta na premissa de que: "os repositórios institucionais surgem como alternativa tanto para agilização do processo de comunicação científica quanto para a gestão do conhecimento científico" (LEITE; COSTA, 2006, p. 11). Os autores ressaltam que os dois processos pressupõem uma orientação para transferência e compartilhamento do conhecimento.

Em um sentido amplo, Di Domenico (2020) baseia-se em Townley (2001) para definir gestão do conhecimento: "a soma de processos de geração e compartilhamento de conhecimento que a empresa julga necessário para consecução de sua missão e objetivos". Compreendendo, assim, um processo que identifica, captura, cria, armazena, sustenta, aplica e compartilha conhecimento, a fim de contribuir para o progresso da organização ou instituição. Nesta perspectiva, as universidades possuem a responsabilidade social de promover a transferência do conhecimento a toda comunidade acadêmica e à sociedade. Dessa forma, iniciativas de gestão do conhecimento contribuem para o aperfeiçoamento e a potencialização do conhecimento científico, de forma a suscitar a geração de novos conhecimentos, a otimização de recursos, o crescimento institucional e o progresso da ciência. Além disso, os repositórios institucionais são ferramentas que contribuem para esses dois processos, tanto de comunicação científica quanto para o de gestão de conhecimento.

\section{COMUNICAÇÃO CIENTÍFICA: DEFINIÇÕES INTRODUTÓRIAS}

A comunicação científica, definida por Garvey e Griffith (1979) é um processo que envolve: "produção", "disseminação" e "uso da informação científica", desde quando o cientista ou pesquisador concebe a ideia de pesquisa até sua constituição como parte do conhecimento científico aceito e validado pelos pares, ou seja, pelos outros cientistas. Meadows (1999) afirma que existem dois tipos de comunicação científica: formal e informal. A comunicação formal é constituída por congressos, artigos científicos, livros, teses, dissertações, entre outros. Já a comunicação informal é engloba canais informais, como emails, telefonemas, relatórios ou conversas entre cientistas.

A conceituação mais recente de comunicação científica sugere "uma ação orientada à divulgação do conhecimento entre os pares" (GAMA; CARVALHO, 2017, p. 4). Os autores afirmam que a comunicação científica é um produto importantíssimo da ciência, pois possibilita a criação de novas pesquisas. "A comunicação científica pode ser entendida como consequência de uma prática de pesquisa, ao mesmo tempo em que é matéria-prima para novos processos de geração de conhecimento". (COSTA; LEITE, 2017, p. 21). Em outras palavras, para que uma pesquisa seja aceita como um conhecimento científico validado, é necessário que esse conhecimento seja comunicado aos outros pesquisadores da área de estudos para que, enfim, essa informação científica seja propagada e reusada a fim de que futuras pesquisas se desenvolvam.

Perspectivas em Gestão \& Conhecimento, João Pessoa, v. 10, n. 3, p. 246-261, set./dez. 2020. 
Rendeiro e Gonçalves (2014) apontam que popularização da ciência, difusão científica, alfabetização científica, vulgarização da ciência e cultura científica, são usados como sinônimos. A diferença sobre a utilização sobre os termos citados, correspondem ao profissional que faz a divulgação da ciência, como professores, jornalistas, educadores, entre outros. A diversidade conceitual também advém da não existência de um conceito totalmente fechado na literatura.

Uma das grandes preocupações dos pesquisadores e cientistas é a falta de conhecimentos básicos da população sobre ciência, o que faz com que os cidadãos se tornem ingênuos, acreditando em qualquer informação. "O desenvolvimento das pesquisas e consequentemente da ciência perde muito do seu papel transformador quando não consegue alcançar a sociedade" (RENDEIRO; GONÇALVES, 2014). Neste contexto a popularização da ciência apresenta-se como uma ação mais horizontal para o intercâmbio das informações científicas para a sociedade.

Germano e Kulesza $(2007$, p. 3) relatam que o termo "popularização da ciência" já era utilizado no Brasil nas décadas de 1960 e 1970. Porém, a expressão mais utilizada no país é "divulgação científica".

Muller, em seu texto "Popularização do conhecimento científico" (2002), ressalta a importância da popularização da ciência, uma expressão que significa, de forma ampla, que o conhecimento científico precisa chegar ao cidadão comum. A autora menciona os principais obstáculos para que a popularização da ciência ocorra de modo pleno: o alto grau de cientificidade na linguagem dos cientistas; ser uma atividade considerada de baixo status para o cientistas que preferem canalizar esforços para comunicar a ciência entre seus pares; distorções propositais dos cientistas em relação ao fazer ciência, como, por exemplo, parcerias entre indústrias e universidades, que camuflam dessa forma os reais riscos das pesquisas - as quais, por muitas vezes, não possuem só o financiamento do governo, precisando de outras agências de fomento e iniciativas privadas -; e, por fim, o fato de que a popularização da ciência pode propagar os interesses das classes dominantes, causando, assim, manipulação da informação científica. Ainda segundo Muller (2002), a falha no processo de popularização da ciência acarretaria um "analfabetismo científico".

Em síntese, assume-se nesta pesquisa que a comunicação científica é mais voltada para os pares, pesquisadores e cientistas; já a divulgação e a popularização científica correspondem a uma ação de comunicação direcionada especificamente para o público em geral. Neste contexto os repositórios são considerados importantes ferramentas de comunicação e divulgação científica, não somente para a comunidade acadêmica, mas para toda a sociedade, facilitando assim o acesso à informação científica, livres das barreiras de custo e acesso. "Recomenda-se a popularização dos repositórios institucionais nas universidades e institutos de pesquisa pela formação de elos entre atores centrais a fim de promover a democratização do acesso aberto à informação científica no Brasil" (GAMA; CARVALHO, 2017, p. 1).

\section{ACESSO ABERTO E A EMERGÊNCIA DOS DIFERENTES TIPOS DE REPOSITÓRIOS}

Existem muitos canais para se propagar a comunicação científica no ambiente acadêmico. Um dos mais consolidados é o periódico científico, porém, por muito tempo a informação científica ficou restrita e sendo monopolizada pelas editoras científicas responsáveis pela gestão destes periódicos. Mesmo em 1990, com o surgimento da web, o conhecimento científico continuava propagando os interesses das próprias editoras, o que culminava em altos custos e barreiras de acesso. Na literatura de Ciência da Informação, esse fato ficou conhecido e definido por Mueller como a "crise dos periódicos". Por esse motivo, no ambiente acadêmico dos últimos anos, o processo de comunicação científica sofreu mudanças

Perspectivas em Gestão \& Conhecimento, João Pessoa, v. 10, n. 3, p. 246-261, set./dez. 2020. 
significativas no que tange à produção, circulação e divulgação dessa comunicação. Cientistas e pesquisadores do mundo inteiro começaram a refletir sobre o movimento de livre acesso à informação científica e, com isso, surgiram as bibliotecas digitais, os portais de periódicos eletrônicos de acesso aberto e os repositórios.

De forma ampla, o acesso aberto é definido, de acordo com as ideias de Freitas (2015), o movimento de acesso aberto à informação científica objetiva tornar a produção científica acessível e disponível na internet, para todos e de forma gratuita e irrestrita. Esse movimento refere-se à disseminação e divulgação ampla e irrestrita dos resultados de pesquisa, principalmente aquelas financiadas por recursos públicos. Ao nosso ver, as pesquisas vêm sendo disponibilizadas e divulgadas para sociedade, sendo, então, uma forma de responsabilidade social da instituição pública.

O acesso aberto pode ocorrer de duas formas: a via dourada, que está relacionada com as publicações de periódicos científicos, sendo que os responsáveis pela disponibilização do material publicado nesses periódicos científicos são os editores, e o acesso a esse material deve ser livre das barreiras de custo e de acesso. Já na via verde, o depósito da pesquisa é feito pelo próprio autor do artigo em um repositório; essa via contempla mais as teses e dissertações (GOMES, 2017, p. 20). "Esse caminho traz de volta o controle da comunicação científica e o devolve aos autores, eliminando essa atribuição das editoras comerciais". (GOMES, 2017, p. 20).

A internet mudou significativamente o sistema de comunicação científica, principalmente no que tange às publicações de periódicos. Ela possibilitou um novo modelo de negócio, o acesso aberto, que visa a disponibilização abertamente do texto integral para qualquer cidadão que possua acesso às redes. $\mathrm{O}$ acesso aberto altera a estrutura de receita de assinaturas de periódicos pagos e editoras científicas, mudando muitas vezes o encargo para 0 autor que publica e não para o pesquisador que acessa. $O$ autor também faz uma crítica ao surgimento dos editores denominados "predatórios", que enviam spams acadêmicos e ganham dinheiro prometendo aos autores publicações rápidas com apenas revisões por pares (BJÖRK, 2017). Por tudo isso, defende-se o surgimento dos repositórios institucionais como uma reação a esse processo de comunicação científica com monopólio das editoras e de periódicos pagos. "A importância do acesso às informações científicas no mundo é indiscutível, levando ao progresso científico e econômico. A condição de acesso fechado às pesquisas científicas deve ser resolvida com a igualdade e o direito de acesso a todos". (CHAN, 2005, tradução nossa).

As discussões dos cientistas em prol do movimento de livre acesso à informação científica, suscitou a criação dos repositórios no Brasil e no mundo através de revisão de literatura, constatamos que o marco do acesso aberto foi com a assinatura das três declarações - Budapest, Bestheda e Berlim - em 2002 e 2003. No Brasil, em 2005, o Instituto Brasileiro de Ciência e Tecnologia (IBICT) lançou o Manifesto Brasileiro de Livre Acesso à Informação Científica, o que impulsionou a criação dos repositórios em várias instituições e universidades brasileiras.

Desde estes movimentos iniciais confirmam-se hoje, a existência de variações na configuração, propósitos e arranjos relacionados aos Repositórios. Por exemplo: "A expressão repositório digital, no contexto do movimento mundial do acesso aberto, é utilizada para denominar os vários tipos de provedores de dados que constituem vias alternativa de comunicação científica" (COSTA; LEITE 2009, p. 165). Já o conceito de RD está ligado à ideia de arquivos abertos e softwares livres, desenvolvendo assim espaço de armazenagem e compartilhamento da informação técnico científica em acesso aberto, através das Tecnologias digitais de comunicação e informação (TSU, 2018). Ainda, "Deve ser o ambiente autêntico para a preservação em longo prazo, dispondo, por exemplo, de ferramentas para a implementação das estratégias de preservação e inserção de padrões de metadados".

Perspectivas em Gestão \& Conhecimento, João Pessoa, v. 10, n. 3, p. 246-261, set./dez. 2020. 
(SANTOS; FLORES, 2015, p. 205). Outro entendimento também é o de que os "Repositórios digitais temáticos ou disciplinares - são vinculados às comunidades específicas, abrangendo uma determinada área ou tema do conhecimento". (NASCIMENTO, 2014, p. 23). Compreendem-se os repositórios digitais ainda, "como uma ferramenta/dispositivo/artefato tecnológico com a finalidade de mediação informacional cujo objetivo é aproximar instituições e autores por meio do compartilhamento da informação científica". (GAMA; CARVALHO, 2017).

Já os Repositórios Institucionais, vem sendo definidos na literatura da seguinte maneira: "É uma base de dados digital e virtual (webbase-data base), de caráter coletivo e cumulativo (memória da instituição), de acesso aberto e interoperável que coleta, armazena, dissemina e preserva digitalmente a produção intelectual da instituição". (DODEBEI,2009, p. 94). Pode ser compreendido também como "Uma biblioteca digital destinada a guardar, preservar e garantir livre acesso, via internet, à produção científica no âmbito de uma dada instituição". (MARCONDES; SAYÃO 2009, p. 9). Ainda "Os repositórios institucionais são considerados principais fontes de acesso aberto, sendo um instrumento destinado a armazenar, preservar a memória institucional e disponibilizar os documentos científicos, fornecendo, assim, visibilidade mundial para a produção científica". (MATIAS, 2015). Uma defesa comumente aceita também é a de que: os repositórios institucionais são estratégias do movimento de acesso aberto, via verde. O seu surgimento e desenvolvimento visam eliminar barreiras referentes o acesso à produção científica, promovendo maior visibilidade das pesquisas em meio acadêmico e sociedade, contribuído, assim, para o desenvolvimento científico e tecnológico do país. Os repositórios constituem importantes ferramentas de gestão, manutenção e preservação da informação científica. (CARVALHO; GOUVEIRA, 2017, p. 4).

Mais recentes, o repositório de dados, tem sido descrito da seguinte maneira: "Os repositórios de dados têm por objetivo armazenamento de dados visando à otimização da recuperação, o que amplia as potencialidades de reuso destes dados entre os pesquisadores. Desta forma, agiliza os processos de investigação e consequentemente, o avanço na ciência." (MONTEIRO, 2017). Complementarmente, "Os repositórios de dados de pesquisa têm como objetivo fundacional garantir o acesso contínuo e aberto - agora e no futuro - aos resultados de pesquisa que se manifestam na forma de dados, e que são considerados parte importante do patrimônio digital da humanidade". (SAYÃO; SALES, 2016, p. 96). Estes repositórios "Armazenam, organizam, descrevem e disseminam dados de pesquisa, auxiliando, assim, a criação de novas pesquisas, evitando a duplicação de esforços do pesquisador, fornecendo transparência no que diz respeito aos auxílios financeiros com o investimento da pesquisa" (SANCHES; VECHIATO; VIDOTTI, 2019, p. 52).

A definição de Repositório de e-prints é a de: "Um tipo de repositório digital que pode ser temático ou institucional, mas que utiliza obrigatoriamente o software E-prints desenvolvido pela University Southamptom, cujos textos que reúne já foram publicados ou não, e estes estão sujeitos a críticas por meio de comentários de outros pesquisadores". (WEITZEL, 2006, p. 26)

\section{METODOLOGIA}

Este artigo configura-se como uma pesquisa descritiva, com abordagem quantitativa e qualitativas. "A pesquisa descritiva tem o objetivo de identificar as características de um determinado problema ou questão e descrever o comportamento dos fatos e fenômenos". (BRAGA, 2007, p. 25).

Metodologicamente, a pesquisa se deu em duas etapas. Primeiramente, foi realizado um levantamento bibliográfico no RCAAP sobre os temas repositório digital, repositório

Perspectivas em Gestão \& Conhecimento, João Pessoa, v. 10, n. 3, p. 246-261, set./dez. 2020. 
institucional e repositório científico, com o objetivo de identificar os diferentes tipos de repositório conceituados na literatura da Ciência da Informação. Como estratégia de busca, utilizamos os seguintes termos de busca: a) em assunto - "repositório digital", "repositório institucional" e "repositório científico"; b) em tipos de materiais - "dissertações de mestrado", "tese" e "tese de doutoramento"; c) em idioma - "português"; d) em tipo de acesso - "livre", "restrito" e "embargado". O período de abrangência da pesquisa foi de "1806 até 2020". Realizamos a pesquisa em 07 de julho de 2020.

A seleção do Repositórios Científicos de Acesso Aberto de Portugal (RCAAP) se deve por este se constituir como um importante diretório agregador de pesquisa e por disponibilizar o acesso de milhares tipos de documentos (artigos científicos, artigos de investigação, capítulos, cartas, conjunto de dados, contributos em revistas, dissertações de mestrado, documentos de trabalho, editoriais, livros, monografias de licenciatura, objetos de conferência, palestras, patentes, preprints, recensões, recursos interativos, relatórios, teses, tese de doutoramentos, textos e outros). Todas estas produções são de caráter científico e acadêmico, disponíveis em repositórios portugueses e brasileiros que possuem interoperabilidade e interligação com o crescente número de centros de investigação, organismos financiadores de pesquisa e instituições de ensino superior na Europa e no mundo.

Como fonte de pesquisa, foi evidenciado neste trabalho as teses e dissertações, pois constituem uma importante fonte primária de informação, contendo conteúdos inéditos e com assuntos específicos, além de representarem canais ágeis de comunicação e divulgação científica.

Referente à coleta dos dados, primeiramente foram separadas as teses e as dissertações do Brasil e de Portugal. Logo após, foi comparado os anos das publicações científicas dos dois países, foram identificados as universidades e institutos que publicaram mais sobre o tema e extraímos as palavras-chave mais utilizadas nessas publicações.

Como campo empírico, foram analisadas as teses e dissertações oriundas das universidades e institutos brasileiros e portugueses: Universidade de Brasília (UNB), Universidade de São Paulo (USP), Instituto Brasileiro de Ciência e Tecnologia/Universidade Federal do Rio de Janeiro (IBICT-UFRJ), Universidade Federal do Ceará (UFC), Universidade Federal do Rio Grande do Norte (UFRN), Universidade Federal do Amazonas (UFAM), Universidade Federal da Bahia (UFBA), Universidade Federal da Paraíba (UFPB), Universidade Federal de Pernambuco (UFPE), Universidade Federal de Santa Maria (UFSM), Universidade Federal de São Carlos (UFSCar), Universidade Estadual Paulista (UNESP), Universidade Federal de Pernambuco (UFPE), Universidade Federal de Mato Grosso Sul (UFMS), Universidade Federal do Estado do Rio de Janeiro (UNIRIO), Fundação Oswaldo Cruz (FIOCRUZ), Universidade Federal de Minas Gerais (UFMG), Universidade Fernando Pessoa, Porto (UFP), Universidade do Porto (U. Porto), Universidade da Beira do Interior (UBI), Universidade do Minho (UMinho), Universidade Nova (UNI.Nova), Universidade de Lisboa (U. Lisboa) e Universidade de Évora (UNIVERSIA).

\section{RESULTADOS E DISCUSSÕES}

Foram identificadas 60 teses, sendo que quatro documentos constituíam duplicidade na base. Das 56 teses e dissertações localizadas, 45 foram produzidas no Brasil e 11 de Portugal. Com o intuito de alcançar nossos objetivos de apresentar o crescimento e o desenvolvimento da literatura sobre RI no Brasil e nos países de língua portuguesa, nesta seção, apresentamos algumas variáveis quantitativas: instituições ou universidades das teses e dissertações defendidas, ano de defesa, tipos de repositórios e palavras-chave.

Perspectivas em Gestão \& Conhecimento, João Pessoa, v. 10, n. 3, p. 246-261, set./dez. 2020. 
Gráfico 1 - Teses e Dissertações disponibilizadas no RCAAP

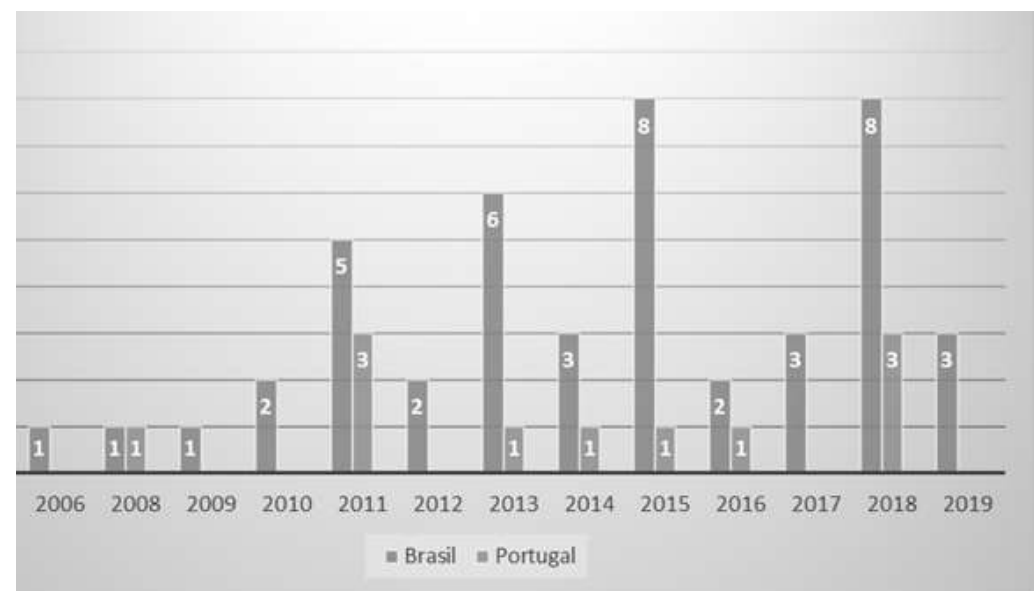

Fonte: Dados da pesquisa (2020)

As teses e dissertações sobre a temática repositório no Brasil e nos países de língua portuguesa são recentes: a produção científica data de 2006 no Brasil e, em Portugal, o primeiro trabalho defendido foi em 2008. A literatura sobre RI aumenta gradativamente nos dois países, com apenas mais um ou dois trabalhos defendidos por ano. Verificamos um crescimento da produção científica em 2011, tanto no Brasil quanto em Portugal. Destacam-se os anos de 2015 e 2018, com oito pesquisas sobre o tema. Nota-se que, em 2019, o tema repositório sofre um declínio, somando apenas três pesquisas no Brasil e nenhuma em Portugal. Isto talvez se justifique por conta do período de coleta de dados (julho de 2020), já que muitas pesquisas produzidas em 2019, poderiam estar ainda tramitando para serem publicadas em 2020.

Gráfico 2 - Tipologias de Repositórios abordados no RCAAP

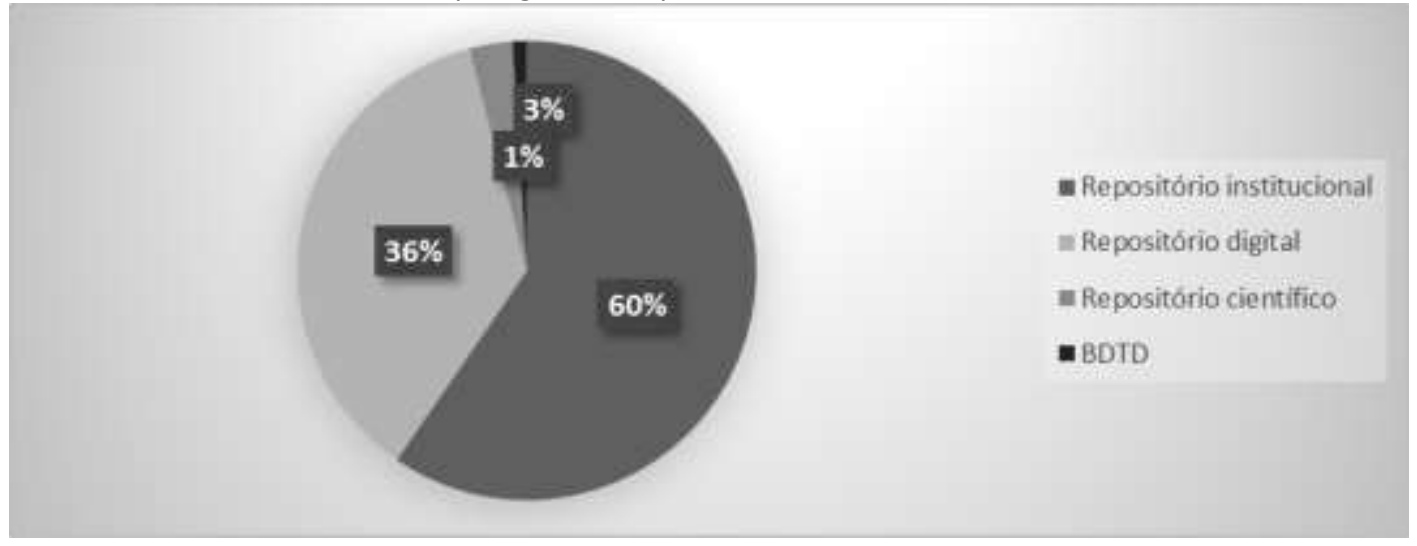

Fonte: Dados da pesquisa (2020) 
Dentre todas as teses e dissertações que tratam do assunto repositório, defendidas no Brasil e em Portugal, $60 \%$ delas abordam o tema repositório institucional, e $36 \%$ tratam do tema repositório digital. Sobre repositório científico, temos apenas três por cento das pesquisas desenvolvidas no âmbito da literatura acadêmica.

Com o objetivo de conhecer os trabalhos concernentes às temáticas repositórios, identificamos também as palavras-chave mais recorrentes na literatura das dissertações e teses da Ciência da Informação: repositório institucional, repositório digital, acesso aberto à informação, comunicação científica, acesso aberto, preservação digital, e informação científica. Outras palavras só foram mencionadas uma ou duas vezes em cada trabalho, como, por exemplo, autoarquivamento, políticas públicas, reuso, entre outras. As palavras-chave constituem importantes recursos para representação temática de um documento, panorama geral da cobertura de um tema e recuperação da informação.

Gráfico 3 - Distribuição dos trabalhos com o tema repositório por universidades brasileiras e portuguesas

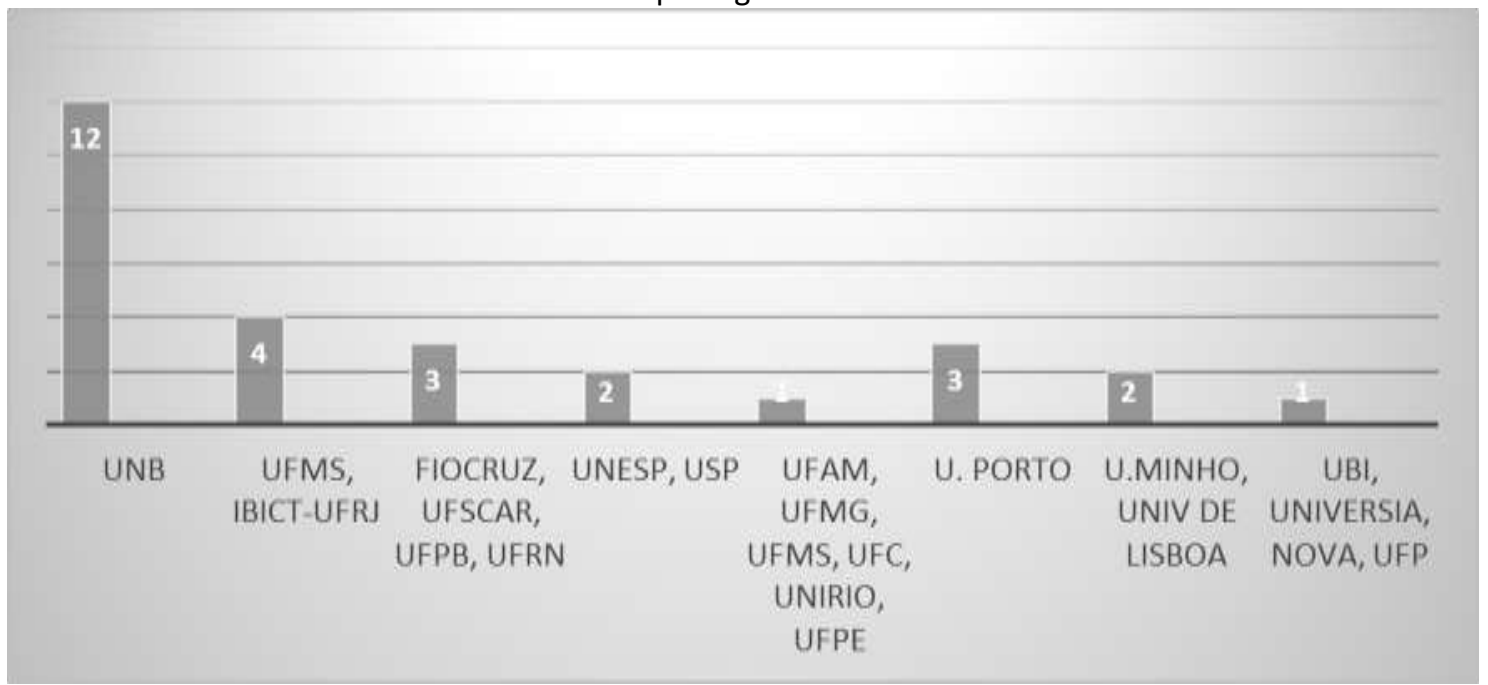

Fonte: Dados da pesquisa (2020)

No que tange ao quantitativo das teses e dissertações distribuídas por universidades ou instituição, a Universidade de Brasília (UNB) é aquela que possui o maior número de teses e dissertações defendidas, com um total de 12 trabalhos. Em seguida, temos a UFSM e o IBICTUFRJ, com quatro pesquisas, e, após, Fiocruz, UFSCar, UFPB e UFRN, com três trabalhos cada. As outras universidades seguem com apenas uma ou duas pesquisas desenvolvidas com a temática repositório. Em Portugal, a Universidade do Porto é a que mais publicou sobre o tema, com três trabalhos. As outras universidades portuguesas também seguem com apenas um ou dois trabalhos.

Foram identificadas ainda a ocorrência das terminologias associadas ao Repositório nas teses e dissertações indexadas no RCAAP, e foram sistematizados os conceitos dos diferentes tipos de repositório identificados, a saber: repositório digital, repositório institucional, repositórios digitais temáticos ou disciplinares, repositório de dados e repositórios de e-prints. É importante ressaltar que os trabalhos analisados contemplaram as variações das definições de repositório na perspectiva da Ciência da Informação.

\subsection{REPOSITÓRIOS ALGUMAS VARIAÇÕES TERMINOLÓGICAS}

Perspectivas em Gestão \& Conhecimento, João Pessoa, v. 10, n. 3, p. 246-261, set./dez. 2020. 
De modo geral, é possível constatar que as nomenclaturas dos repositórios variam de acordo com os tipos de materiais nele inseridos. Santos Júnior (2010), associa o conceito de "repositório digital" como sinônimo ao conceito de biblioteca digital, "biblioteca virtual", "biblioteca eletrônica", "biblioteca sem paredes", "biblioteca polimidia", "biblioteca do futuro" ou "biblioteca biônica". Grosso modo, repositórios digitais, ou bibliotecas digitais, significam "plataformas para armazenamento e documentos digitais" (SANTOS JÚNIOR, 2010, p. 35).

O que diferencia um repositório digital de um repositório institucional, é que o institucional contempla as pesquisas acadêmicas e deve seguir a filosofia do acesso aberto Open Archives Initiative (OAI), sobretudo as pesquisas subsidiadas pelas agências de fomento, como CAPES, CNPQ, FAPESP, entre outras (SANTOS JÚNIOR, 2010, p. 35).

A primeira conceituação de repositório institucional surgiu em 2002, sendo definido por Crow como coleções digitais que capturam a produção intelectual de uma universidade ou instituição de pesquisa, constituindo, assim, um indicador de qualidade acadêmica. Fornece, assim duas respostas à comunidade acadêmica: reduzir o monopólio das editoras dos periódicos pagos, trazendo um alívio econômico e maior relevância para as instituições de pesquisa; e servir como indicador tangível de qualidade de uma universidade, para demonstrar relevância científica, social e econômica de suas atividades de pesquisa, aumentando a visibilidade, o status e o valor público da instituição (CROW, 2002).

Um dos primeiros repositórios a surgir foi, segundo Lynch (2003) o repositório digital temático The Scholarly Journal Archive (JSTOR) abrangendo a preservação de jornais científicos em uma dada área do conhecimento. Mais tarde, a sua tipologia evoluiu para o repositório institucional, ficando a critério e sob a universidade oferecer aos membros de sua comunidade, visando ao gerenciamento e disseminação dos materiais digitais criados pela instituição e pelos membros de sua comunidade (LYNCH, 2003).

Sobre o Repositório digital, um dos estudos pioneiros sobre a categorização dos repositórios foi realizado por Leite (2009, p. 20), que conceitua repositório digital contemplando vários tipos de provedores de dados que têm por objetivo gerenciar a informação científica, constituindo, assim, uma importante ferramenta de comunicação científica. $\mathrm{O}$ autor categoriza o repositório digital em três tipologias:

1) repositórios institucionais: refere-se à produção científica de uma dada instituição como universidades e institutos de pesquisa;

2) repositórios temáticos ou disciplinares: refere-se à produção científica de comunidades científicas ou específicas, como área de um conhecimento particular;

3) repositórios de teses e dissertações: são repositórios que, como o próprio nome já indica, contêm apenas teses e dissertações, a exemplo da BDTD (Biblioteca Digital de Teses e Dissertações do Instituto Brasileiro de Ciência e Tecnologia).

Nascimento (2014, p. 23), baseado em Leite (2009, p. 20), aponta que os repositórios digitais podem ser subdivididos em dois: temáticos ou institucionais. Os temáticos são voltados para uma determinada área ou tema de pesquisa, independentemente de sua instituição. E os repositórios digitais institucionais contemplam uma dada instituição. $O$ repositório digital seria então uma tipologia mais ampla de repositório, e o institucional, estaria sempre atrelado a uma instituição de pesquisa.

Repositório institucional seria uma tipologia de repositório que tem por objetivo concentrar toda a produção científica de uma instituição, fornecendo interoperabilidade e seguindo a filosofia do Open Archive Initiative, "visando a difusão da ciência e a proteção da propriedade intelectual" (QUEIROZ, 2015, p. 35).

Conforme a necessidade de agilidade e transparência no processo de comunicação científica, surgem outros tipos de repositório mais recentes, como os de dados e os de eprints. "Os repositórios de dados são uma evolução dos repositórios digitais no qual o uso de repositórios para a divulgação de trabalhos científicos se iniciou com os repositórios

Perspectivas em Gestão \& Conhecimento, João Pessoa, v. 10, n. 3, p. 246-261, set./dez. 2020. 
temáticos" (MONTEIRO, 2017, p. 34). Estes podem ser definidos, conforme o autor, como um ambiente digital que tem por finalidade o armazenamento, a preservação, a organização, a recuperação, a disseminação e o reuso dos dados provenientes das pesquisas científicas.

No contexto de aceleração do processo de comunicação científica e do avanço da ciência, é desenvolvida uma nova tipologia de repositório, os preprints, compostos por material ainda não avaliado pelos pares. "Os RI não necessariamente realizam avaliação por pares, apenas disponibilizam seu conteúdo gratuitamente para o mundo. Eles podem conter preprints (sem avaliação por pares) ou pós-print (com avaliação por pares)" (SANTOS JÚNIOR, 2010).

A título de exemplo, em 2020, durante pandemia de covid-19, foram lançadas duas iniciativas de repositório de preprints: preprints.ibict.br (IBICT-UFRJ); e a preprints.scielo.org/index.phd/Scielo (SCIELO preprints). Andrade (2018) afirma que os repositórios podem ser classificados em institucionais, temáticos e de objetos de aprendizagem. "As vantagens dos repositórios, identifica-se que eles vão além da academia, beneficiam a sociedade como um todo ao disponibilizar publicações científicas sem as restrições impostas por editoras comerciais" (ANDRADE, 2018, p. 44). Nessa definição o autor usa outra expressão para o repositório-objetos de aprendizagem -, uma nomenclatura que não é comum nas teses e dissertações da Ciência da Informação.

Autores portugueses, como Andrade (2018) e Janeiro (2014), conceituam Repositório Institucional através da mesma percepção dos autores brasileiros, sendo definidas como: ferramentas de armazenamento que fornecem suportes às atividades de pesquisa, ensino e aprendizagem. Sua criação é estimulada pela instauração mundial do acesso aberto, e tem por filosofia o amplo acesso à informação científica, partilha e reuso dessa informação. Os repositórios têm por objetivo divulgar a produção científica dos membros de uma instituição (JANEIRO, 2014, p. 25).

Shintaku, Duque e Suaiden (2014, p. 2) afirmam que o conceito de repositório digital está fortemente atrelado a duas áreas do conhecimento: Ciência da Informação e Ciência da Computação. Porém, com abordagens diferentes nas duas áreas, na Ciência da Computação, o conceito está mais relacionado ao compartilhamento de softwares e algoritmos, sendo programas que têm por finalidade compartilhar, desenvolver e distribuir aplicativos. Já na Ciência da Informação, o conceito de repositório tem um viés mais científico, com estudos mais voltados para organização e gestão da informação, tendo por objetivo a comunicação científica, principalmente no que tange à disseminação da informação e do conhecimento em acesso aberto.

\section{CONSIDERAÇÕES FINAIS}

Os repositórios surgiram como uma ferramenta de acesso aberto, visando a criação de arquivos em formato digital disponível para toda comunidade acadêmica e para toda a sociedade em geral, independente das barreiras de custo e acesso, e tendo a finalidade de armazenar, organizar, preservar, disponibilizar e disseminar a informação científica. As vantagens dos repositórios são a diminuição das barreiras de acesso a produção do conhecimento, a criação de condições para a maior visibilidade para a produção científica, a preservação digital de pesquisas científicas e a potencialização das condições para o aumento das citações de pesquisas dos autores. Através dos repositórios, também é possível mapear a produção científica de determinado autor ou área do conhecimento.

No século XXI, com o desenvolvimento das novas tecnologias digitais de informação e comunicação, há também um avanço no processo de comunicação científica - como, a título de exemplo, os repositórios -, representando novas formas de ampliar o acesso à informação científica. Nesse sentido, essa pesquisa contemplou os repositórios como uma forma de 
preservar, comunicar, propagar, divulgar e circular a ciência. A preocupação com o livre acesso à informação se deu em todas as áreas do conhecimento. Os profissionais da informação atuantes em bibliotecas, arquivos, museus, institutos de memória e universidades, também ressignificaram o processo de armazenamento, preservação, organização, recuperação e divulgação da informação científica. É diante desse cenário que surgem os repositórios institucionais. Mas, para que a filosofia do acesso aberto realmente ocorra nas universidades e instituições, faz-se necessário um intenso trabalho de conscientização entre cientistas e pesquisadores em prol da sociedade.

De acordo com as informações obtidas através da análise quantitativa e qualitativa sobre "repositório digital", "repositório institucional" e "repositório científico", constatou-se que este é um tema que aparece ainda tímido como objeto de investigação científica e é também recente nas teses e dissertações em universidades e institutos brasileiros e portugueses. Assim, foi objetivo deste trabalho apresentar um panorama geral sobre a temática repositório nestes países, ressaltando a importância de refletirmos sobre as vantagens destes para a comunidade acadêmica e para toda a sociedade, contribuindo, assim, para que os pesquisadores realizem mais pesquisas sobre esta temática.

Conforme a análise qualitativa das teses e dissertações brasileiras e portuguesas, foi constatado que os repositórios possuem várias tipologias, e que estas variam de acordo com o tipo de material reunido, como teses, dissertações, artigos e materiais ainda não validados pelos pares, como os dados de pesquisa e os preprints. Também podem ser classificados de acordo a área de estudo ou a instituição de pesquisa ao qual encontram-se inseridos. Há um consenso entre os autores de que o conceito mais amplo é o de repositório digital. Os autores brasileiros e portugueses conceituam repositório sob um mesmo prisma; em alguns trabalhos, é possível identificar uma certa confusão conceitual.

Foi identificado também que o conceito mais utilizado é o de repositório institucional, pois a maioria dos trabalhos é voltada para esse tema. Em seguida, as pesquisas relatam a temática repositório digital. Sobre o repositório de dados, de preprints e os repositórios digitais científicos, existem poucos trabalhos abordando essas tipologias, contabilizando apenas um ou dois trabalhos por instituição.

O entendimento sobre as diferentes variações terminológicas sobre os Repositórios, utilizadas nas pesquisas produzidas e publicadas em Língua Portuguesa, sejam elas produzidas no Brasil ou em Portugal (países selecionados neste estudo) poderá otimizar a identificação mútua de pesquisas para citações, de pesquisadores para intercâmbios entre grupos de pesquisas, de convergência de experiências no desenvolvimento de produtos e serviços. Assim, não foi intuito deste estudo sugerir qualquer perspectiva de padronização terminológica, tendo sido seu objetivo, apresentar apenas uma discussão sobre as varrições terminológicas até então utilizadas para descrever, caracterizar e diferenciar os Repositórios.

Por fim, registra-se a necessidade de reflexões mais aprofundadas sobre esses temas e de estudos em outras bases de dados, principalmente novas pesquisas que apontem o progresso do tema repositório.

\section{REFERÊNCIAS}

ANDRADE, Morgana Carneiro de. Interoperabilidade semântica entre repositórios digitais científicos: um perfil de aplicação de metadados baseado nas necessidades de informação em Oncologia. 2018. 457 f. Tese (Doutorado) - Universidade do Minho, Minho, 2018. Disponível em: http://repositorium.sdum.uminho.pt/handle/1822/58953. Acesso em: 20 jun. 2020.

Perspectivas em Gestão \& Conhecimento, João Pessoa, v. 10, n. 3, p. 246-261, set./dez. 2020. 
BRAGA, Kátia Soares. Aspectos relevantes para seleção de metodologia adequada à pesquisa social em Ciência da Informação. In: MUELLER, S. Métodos para a pesquisa em Ciência da Informação. Brasília: Thesauros, 2007.

BJÖRK, Bo-Christer. Open access to scientific articles: a review of benefits and challenges. Internal and emergency medicine, v. 12, n. 2, p. 247-253, 2017. Disponível em: https://link.springer.com/article/10.1007/s11739-017-1603-2. Acesso em: 20 de nov. 2020.

CARVALHO, Ana Maria Ferreira de; GOUVEIA, Fábio Castro. Repositórios institucionais de acesso aberto: adequação às novas métricas da web. Reciis - Rev. Eletrôn. Comum. Inf. Inov. Saúde, Rio de Janeiro, v. 11, supl., nov. 2017. Disponível em: https://www.reciis.icict.fiocruz.br/index.php/reciis/article/view/1420. Acesso em: 06 jul. 2020.

CHAN, Leslie et al. Improving access to research literature in developing countries: challenges and opportunities provided by Open Access. In: WORLD LIBRARY AND INFORMATION CONGRESS: IFLA GENERAL CONFERENCE AND COUNCIL Proceedings... Noruega: IFLA, 2005. Disponivel em: https://link.springer.com/article/10.1007/s11739-017-1603-2. Acesso em: 20 nov. 2020.

COSTA, Michelli Pereira da; LEITE, Fernando Cesar Lima. Repositórios institucionais na América Latina e o acesso aberto à informação científica. Brasília: IBICT, 2017. Disponível em: https://repositorio.unb.br/handle/10482/23202. Acesso em: 15 ago. 2020.

COSTA, Suely Maria de Souza; LEITE, Fernando Cesar Lima. Insumos conceituais e práticos para iniciativas de repositórios institucionais de acesso aberto à informação científica em bibliotecas de pesquisa. In: SAYÃO, Luís (org.). Implantação e gestão de repositórios institucionais: políticas, memória, livre acesso e preservação. Salvador: EDUFBA, 2009. Disponível em: https://repositorio.ufba.br/ri/bitstream/ufba/473/3/implantacao repositorio web.pdf. Acesso em 21 out. 2020.

COSTA, Michelli Pereira da. Características e contribuições da via verde para o acesso aberto à informação científica na América Latina. 2014. 226 f. Dissertação (Mestrado em Ciência da Informação) - Universidade de Brasília, Brasília, 2014. Disponível em: https://repositorio.unb.br/handle/10482/15687. Acesso em: 18 abr. 2019.

CROW, R. The case for institutional repositories: ASPARC position paper. Washington, DC: Scholarly Publishing \& Academic Resources Coalition, 2002. Disponível em: http://www.arl.org/sparc/IR/ir.htm. Acesso em: 20 de nov. 2020.

DI DOMENICO, Q. et al. Gestão do conhecimento em bibliotecas sob a perspectiva da abordagem qualitativa: uma revisão sistemática. Perspectivas em Gestão \& Conhecimento, v. 10 , n. 2, p. 203-222, 25 ago. 2020. Disponível em: https://periodicos.ufpb.br/ojs2/index.php/pgc/article/view/47917/31155. Acesso em: 20 de nov. 2020.

DODEBEI, Vera. Repositórios institucionais: por uma memória criativa no ciberespaço. In: SAYÃO, Luiz Fernando et al. (org.). Implantação e gestão de repositórios institucionais: 
políticas, memória, livre acesso e preservação. Salvador: EDUFBA, 2009, 365 p. Disponível em: https://repositorio.ufba.br/ri/bitstream/ufba/473/3/implantacao repositorio web.pdf. Acesso em: 21 out. 2020.

FREITAS, Marília Augusta de. Diretrizes para o depósito da produção científica em repositórios institucionais. 2015. 214 f. Tese (Doutorado em Ciência da Informação) Universidade Federal de Brasília, Brasília, 2015. Disponível em: https://repositorio.unb.br/bitstream/10482/19189/1/2015 MariliaAugustadeFreitas.pdf.

Acesso em: 19 ago. 2019.

GAMA, Ivanilda de Oliveira; CARVALHO, Lidiane dos Santos. Tendências e perspectivas de pesquisa sobre repositório digitais no Brasil: uma análise de Redes Sociais (ARS). Reciis- Rev. Eletron. Com. Inf. Inov. Saúde, Rio de Janeiro, v. 11, supl., nov. 2017. Disponível em: www.reciis.icict.fiocruz.br. Acesso em: 20 jan. 2019.

GARVEY, W. D.; GRIFFITH, B. G. Communication and information processing within scientific disciplines: empirical findings. In: GARVEY, W. D. Communication: the essence of science. Oxford: Pergamon Press, 1979.

GOMES, Anilza Rita de Souza. Práticas de disponibilização da produção científica da UFBA: contribuição à política institucional de acesso aberto. 2017. 113 f. Dissertação (Mestrado) Instituto de Humanidades, Artes e Ciências Professor Milton Santos, Universidade Federal da Bahia, Salvador, 2017. Disponível em: https://repositorio.ufba.br/ri/handle/ri/24947. Acesso em: 15 out. 2019.

JAMBEIRO, Othon; ROSA et al. Comunicação científica: estudo de caso sobre uma política de acesso aberto para a produção acadêmica. Perspectivas em Gestão \& Conhecimento, João Pessoa, v. 2, n. 2, p. 143-155, jul./dez. 2012. Disponível em: https://periodicos.ufpb.br/ojs2/index.php/pgc/article/view/14362/0. Acesso em: 21 out. 2020.

JANEIRO, Joana Isabel Aires Góis. O utilizador como co-criador de serviços e conteúdo. Relatório de Estágio. 2014. 80 f. (Mestrado) - Programa de Pós-Graduação em Ciência da Informação e Biblioteconomia, Universidade Nova, Porto, 2014. Disponível em: https://run.unl.pt/handle/10362/13626. Acesso em: 05. abr. 2019.

GERMANO, Marcelo Gomes; KULESZA, Wojciech Andrzej. Popularização da ciência: uma revisão conceitual. Caderno Brasileiro de Ensino de Física, Florianópolis, v. 24, n. 1, p. 7-25, ago. 2008. Disponível em: https://periodicos.ufsc.br/index.php/fisica/article/view/1546. Acesso em: 14 ago. 2020.

LEITE, Fernando César Lima; COSTA, Sely. Repositórios institucionais como ferramentas de gestão do conhecimento científico no ambiente acadêmico. Perspect. ciênc. inf., Belo Horizonte, v. 11 , n. 2, p. 206-219, mai./ago. 2006. Disponível em: http://portaldeperiodicos.eci.ufmg.br/index.php/pci/article/view/323. Acesso em: 20 ago. 2020.

LEITE, Fernando César Lima. Como gerenciar e ampliar a visibilidade da informação científica brasileira: repositórios institucionais de acesso aberto. Brasília: IBICT; 2009.

Perspectivas em Gestão \& Conhecimento, João Pessoa, v. 10, n. 3, p. 246-261, set./dez. 2020. 
LYNCH, Clifford, A. Institutional repositories, infrastucture for scholarship in the digital age. Arl Bimonthly Report, v. 226, p. 1-7, fev. 2003.

MARCONDES, Carlos Henrique; SAYÃO, Luís Fernando. À guisa de introdução: repositórios institucionais e livre acesso. In: SAYÃO, Luís Fernando et al. (org.). Implantação e gestão de repositórios institucionais: políticas, memória, livre acesso e preservação. Salvador: EDUFBA, 2009, 365 p.

MATIAS, Mesailde Souza de Oliveira. Base referencial para o povoamento de repositórios institucionais: coleta automatizada de metadados da Plataforma Lattes. 2015. $86 \mathrm{f}$. Dissertação (Mestrado) - Centro de Educação em Ciências Humanas, Programa de PósGraduação em Ciência, Tecnologia e Sociedade, Universidade Federal de São Carlos, São Carlos, 2015. Disponível em: https://repositorio.ufscar.br/handle/ufscar/6932. Acesso em: 19 abr. 2020.

MONTEIRO, Elisabete Cristina de Souza de Aguiar. Direitos autorais nos repositórios de dados científicos: análise sobre planos de gerenciamento dos dados. 2017. 115 f. Dissertação (Mestrado) - Faculdade de Filosofia e Ciências, Programa de Pós-Graduação em Ciência da Informação, Universidade Estadual Paulista, Marília, 2017. Disponível em: https://repositorio.unesp.br/handle/11449/149748. Acesso em: 19. abr. 2020.

MUELLER, Suzana Pinheiro Machado. Popularização do conhecimento científico. DataGramaZero: Revista de Ciência da Informação, [s. I.], v. 3, n. 2, abr. 2002. Disponível em: https://repositorio.unb.br/handle/10482/990. Acesso em: 20 jun. 2020.

NASCIMENTO, Aline Vieira do. Identificando fatores de sucesso para as bibliotecas digitais e Repositórios Institucionais. 2014. 118 f. Dissertação (Mestrado) - Instituto Brasileiro de Informação em Ciência e Tecnologia, Programa de Pós-Graduação em Ciência da Informação, Universidade Federal do Rio de Janeiro, Rio de Janeiro, 2014. Disponível em: http://www.repositorio.ufc.br/handle/riufc/8350. Acesso em: 18 abr. 2019.

RCAAP. Disponível em: https://www.rcaap.pt/search.jsp. Acesso em: 10 fev. 2020.

QUEIROZ, Nirlange Pessoa de. Avaliação do repositório institucional da Universidade Federal do Ceará na perspectiva e difusão da informação científica. 2015. 115 f. Dissertação (Mestrado) - Universidade Federal do Ceará, 2015. Disponível em: http://www.repositorio.ufc.br/handle/riufc/11069. Acesso em: 20 abr. 2019.

RENDEIRO, Manoel; GONÇALVES, Carolina. Divulgação e popularização da ciência: relato de experiência do projeto "Ciência às 7 e meia". Revista Areté: Revista Amazônica de Ensino de Ciências, Amazonas, v. 7, n. 13, p. 222-231, maio 2017. Disponível em: http://periodicos.uea.edu.br/index.php/arete/article/view/117. Acesso em: 14 ago. 2020.

SANCHEZ, Fernanda Alves; VECHIATO, Fernando Luiz; VIDOTTI, Silvana Aparecida Borsetti Gregório. Encontrabilidade da informação em repositórios de dados: uma análise do DataONE. Informação \& Informação, Londrina, v.24, n.1, p.51-79, mar. 2019. Disponível em: http://www.uel.br/revistas/uel/index.php/informacao/article/view/30725. Acesso em: 22 out. 2020.

Perspectivas em Gestão \& Conhecimento, João Pessoa, v. 10, n. 3, p. 246-261, set./dez. 2020. 
SANTOS, Henrique Machado dos; FLORES, Daniel. Repositórios digitais confiáveis para documentos arquivísticos: ponderações sobre a preservação em longo prazo. Perspect. ciênc. inf., Belo Horizonte, v. 20, n. 2, p. 198-218, jun. 2015. Disponível em: http://www.scielo.br/scielo.php?script=sci arttext\&pid=S141399362015000200198\&lng=en\&nrm=iso. Acesso em: 21 out. 2021.

SANTOS JUNIOR, Ernani Rufino dos. Repositórios institucionais de acesso livre no Brasil: estudos Delfos. 2010. 177 f. Dissertação (Mestrado)- Faculdade de Ciência da Informação, Programa de Pós-Graduação em Ciência da Informação, Universidade de Brasília, Brasília, $2010 . \quad$ Disponível em: https://www.researchgate.net/publication/45456905 Repositorios institucionais de acesso livre no Brasil estudo Delfos. Acesso: 20 de fev. 2020.

SAYÃO, Luís Fernando; SALES, Luana Farias. Algumas considerações sobre os repositórios digitais de dados de pesquisa. Informação \& Informação, Londrina, v. 21, n. 2, p. 90-115, maio/ago., 2016. Disponível em: http://www.uel.br/revistas/uel/index.php/informacao/article/view/27939. Acesso em: 20 out. 2020.

SHINTAKU, Milton; DUQUE, Cláudio Gottschalg; SUAIDEN, Emir José. Análise sobre o uso das tendências tecnológicas nos repositórios brasileiros. Pesq. Bras. em Ci. da Inf. e Bib., João Pessoa, $\quad$ v. $\quad 9, \quad$ n. 2 2, 2014.2 Disponível em: https://periodicos.ufpb.br/ojs/index.php/pbcib/article/view/21547. Acesso em: 20 out. 2020.

TOWNLEY, C. T. Knowledge management and academic libraries. College and Research Libraries, [s. I.], v. 62, n. 1, p. 44-55, 01 jan. 2001.

TSU, Maria Aparecida Andrade de Oliveira. Os repositórios digitais da produção técnicocientífica dos Institutos Federais de Educação, Ciência e Tecnologia do Brasil: uma análise da comunicação científica no ambiente virtual. 2018. 116 f. Dissertação (Mestrado) - Instituto Superior de Contabilidade e Administração do Porto, Instituto Politécnico do Porto, Porto, 2018. Disponível em: https://recipp.ipp.pt/handle/10400.22/13009?locale=en. Acesso em: 14 ago. 2020.

WEITZEL, Simone da Rocha. O mapeamento dos repositórios institucionais brasileiros: perfil e desafios. Encontros Bibli: revista eletrônica de biblioteconomia e ciência da informação, Florianópolis, v. 24, n. 54, p. 105-123, jan. 2019. Disponível em: https://periodicos.ufsc.br/index.php/eb/article/view/1518-2924.2019v24n54p105. Acesso em: 14 ago. 2020.

WEITZEL, Simone da Rocha. Os repositórios de e-prints como nova forma de organização da produção científica: o caso da área das ciências da comunicação no Brasil. 361 f. 2006. Tese (Doutorado) - Escola de Comunicação e Artes, Departamento de Biblioteconomia e Documentação, Universidade de São Paulo, São Paulo, 2006.

Artigo recebido em 23/09/2020 e aceito para publicação em 22/12/2020

Perspectivas em Gestão \& Conhecimento, João Pessoa, v. 10, n. 3, p. 246-261, set./dez. 2020. 